\title{
BMJ Open Child transport injuries and deaths in Lebanon: a multicentre retrospective study
}

\author{
Samar Al-Hajj (D , ${ }^{1}$ Sebouh Arjinian, ${ }^{2}$ Zahraa Hamadeh, ${ }^{2}$ Elie Al-Zaghrini, ${ }^{3}$ \\ Khalil El Asmar ${ }^{4}$
}

To cite: Al-Hajj S, Arjinian S, Hamadeh Z, et al. Child transport injuries and deaths in Lebanon: a multicentre retrospective study. BMJ Open 2020;10:e037973. doi:10.1136/ bmjopen-2020-037973

- Prepublication history for this paper is available online. To view these files, please visit the journal online (http://dx.doi. org/10.1136/bmjopen-2020037973).

SA and KEA contributed equally.

Received 03 December 2019 Revised 24 August 2020 Accepted 13 September 2020

Check for updates

(C) Author(s) (or their employer(s)) 2020. Re-use permitted under CC BY-NC. No commercial re-use. See rights and permissions. Published by BMJ.

${ }^{1}$ Health Management and Policy Department, Faculty of Health

Sciences, American University of Beirut, Beirut, Lebanon

${ }^{2}$ American University of Beirut,

Beirut, Lebanon

${ }^{3}$ Emergency Medicine

Department, Faculty of

Medicine, Lebanese American University, Beirut, Lebanon

${ }^{4}$ Epidemiology and Population Health Department, Faculty of Health Sciences, American University of Beirut, Beirut, Lebanon

Correspondence to

Dr Samar Al-Hajj;

sh137@aub.edu.lb

\section{ABSTRACT}

Introduction Road traffic injury (RTI) constitutes the leading cause of deaths and disabilities for individuals aged 5-29 years globally. Lebanon suffers from a high toll of transport mortality and morbidity, though accurate and reliable RTI data are limited. The aim of this study is to assess the prevalence and the characteristics of child transport injuries and deaths in Lebanon and to determine their outcomes and associated risk factors.

Methods We conducted a multicentre retrospective study to analyse data on transport injuries and deaths for children aged $0-17$ years over a 3-year period (2015-2017). Data were captured from multiple sources, including police reports and the emergency departments of 30 hospitals across the country. We performed logistic regression models to examine the effects and test the association of multiple simultaneous factors on the child injury outcome and severity.

Results A total of 3,033 cases of child transport injuries and 237 fatalities were collected. The majority of the cases were males $(73 \%)$ (mean $(S D)$ age $=11( \pm 5)$ years). Transport victims were Lebanese $(66.5 \%)$ and Syrian refugees (27.9\%). The most commonly reported factor contributing to child's RTI was a child riding in high-speed vehicles (25\%) and the most affected body regions were upper and lower extremities (29.9\%), followed by head injuries (26.1\%). Pedestrians had higher odds of sustaining fatal injuries compared to four-wheel vehicle occupants $(\mathrm{OR}=1.6 ; 95 \% \mathrm{Cl}: 1.17$ to 2.27$)$. Older age groups of $6-14$ years $(0 \mathrm{R}=0.51 ; 95 \% \mathrm{Cl}: 0.79$ to 0.69$)$ and $15-17$ years $(\mathrm{OR}=0.41 ; 95 \% \mathrm{Cl}: 0.30$ to 0.61$)$ had lower odds of dying from transport injuries compared to the younger age group of $0-5$ years.

Conclusion Child transport injury is a major public health problem in Lebanon. Findings from this study urge policymakers and health professionals to implement evidencebased child transport safety policies and behaviour change programs to reduce child transport injuries and deaths.

\section{INTRODUCTION}

Road traffic injury (RTI) constitutes the leading cause of deaths or disabilities for individuals aged 5-29 years globally. ${ }^{1-3}$ In 2016 , RTIs claimed the lives of 1.35 million individuals and injured 50 million more, many of whom were left with short-term and longterm disabilities. ${ }^{3}$ The burden of transport

\section{Strengths and limitation of this study:}

The study combines multiple sources of data (hospital patient records and police reports) to reveal for the first-time evidence on the child transport injuries and deaths in Lebanon.

- Pedestrians had higher odds of sustaining fatal injuries compared to four-wheel vehicles occupants.

- The younger age group of $0-5$ years had higher odds of dying from transport injuries compared to the older age group of 15-17 years.

- Refugee children had two times higher odds of dying as a result of road injuries as pedestrians compared to Lebanese children.

- The study accessed secondary data, which might hinder the collection of essential elements related to the injury mechanism and severity as well as road safety measures adopted.

injuries is disproportionally distributed globally with almost $85 \%$ of the global RTI deaths and $90 \%$ of disability-adjusted life years occurring in low-income and middle-income countries with an estimated death rate of 27.5 per 100000 population, almost three times higher than the rate reported in high-income countries. ${ }^{3}{ }^{4}$ This high injury mortality rate is mainly due to the increased motorisation industry coupled with the lack of road infrastructures and government enforcement of traffic safety legislations.

Children are vulnerable road victims, particularly in low-income and middleincome countries, where the rate of child transport fatalities is approximately six times higher compared to high-income countries. ${ }^{4}$ Two-thirds of global child's RTIs occur in South-East Asia and the Western Pacific regions; nevertheless, the Middle East and North Africa region ranks the highest in the world for child fatal transport injuries. ${ }^{5-11}$ Lebanon, like many Middle Eastern countries, assumes high transport morbidity and mortality rates as a result of lax government safety regulations and the absence of law 
enforcement, ${ }^{12-15}$ leading to limited compliance with several road safety measures (i.e. seatbelts/helmets use, child restraint systems and speed reduction in children's zone). According to WHO's Road Status Report 2018, the rate of transport deaths in Lebanon was estimated at 18.1 per 100000 population, with more than half of those road victims below the age of 30 years. ${ }^{312-15}$ More recently, the Syrian conflict and the massive influx of Syrian refugees into Lebanon further challenged the Lebanese healthcare sector and increased the transport injury burden, particularly, that refugees are frequent road users (e.g. motorcyclists, pedestrians and street sellers).$^{16-20}$ The neighbouring Syrian war resulted in the settlement of nearly 1.5 million Syrian refugees in Lebanon, increasing its population by nearly $30 \%$ to reach 6.8 million by 2020 , with a median age of 29.6 years. ${ }^{1721} 22$ This constant transformation in the demographic make-up and socioeconomic conditions of the Lebanese population coupled with the lack of road safety policies exacerbated the current road injury problem in Lebanon.

Despite its substantial burden, child transport injury suffers from major under-reporting in Lebanon, which hinders the accurate assessment of the actual burden. Lebanon, with itsresource-limited healthcare system, lacks a national injury surveillance system and consequently accurate and reliable road injury data are absent. The primary objective of this study is to quantify the prevalence of child transport injuries and fatalities in Lebanon, and to assess their characteristics and determine their outcomes and associated risk factors. Evidence from this study will be adopted to design and develop road safety awareness programmes and to inform strategic child restraint regulations and policies aiming at reducing child transport injuries and deaths and promoting child safety and well-being.

\section{MATERIALS AND METHODS}

This study was a retrospective review of police reports and hospital patient records for children aged $0-17$ years, who sustained a transport injury or death in Lebanon. Any child transport victim (eg, passengers or drivers of moving vehicles, pedestrians, cyclists, motorcyclists or motorcycle riders) who sustained a fatal or non-fatal transport injury was included in the study. Children treated and released at any emergency department of the participating hospitals were included in the study. Based on data availability and completeness, the data capturing process was restricted to transport injuries occurring during the period from 2015 to 2017. To gain a deeper understanding of the circumstances surrounding each type of road collision injury, hospital data were complemented with police collision reports, obtained from the Lebanon's Internal Security Forces. Due to the retrospective nature of the study, patients were not involved in the study conception and design nor were they involved in patients' recruitments and study.
We adopted a cluster random sampling strategy to select a representative subset of hospitals from across Lebanon's eight governorates. Drawing from a list of private and public hospitals, seven hospitals were randomly sampled from each governorate, using the probability proportional to size technique to ensure that the number of hospitals selected is proportional and reflected the governorate population size. Nonetheless, some of the selected hospitals were not included in the study due to the following reasons: (1) hospitals had missing and incomplete ED data and (2) hospitals decided to withdraw their 'consent to participate' and denied the researchers' access to patients' records. The final number of hospitals included in the study was 30 (Appendix A). Selected hospitals were a mix of public and private hospitals. All cases meeting the inclusion criteria at the participating hospitals were included in the study, without further sampling at the hospital level. We aggregated the governorates into the following five regional districts: Beirut, Mount Lebanon, North and Akkar, beqaa and Baalbek, and South and Nabativeh.

We designed a child transport injury surveillance form on the RedCap. ${ }^{23}$ Inspired by existing injury surveillance systems, including the Canadian Hospitals Injury Reporting and Prevention Program and the WHO's Injury Surveillance Guidelines, ${ }^{2425}$ we developed the form to document all details related to child demographics, victims involved (ie, driver/passenger, pedestrian, cyclist and motorcyclist), transport mode (four-wheeled vehicle, motorcycle and bicycle), collision information (ie, cause, location, weather conditions, time and car type), nature of injury, clinical presentation (injury nature and body part) and disposition (treated and released, admitted and death). Collision information was abstracted from police reports, while injury clinical presentation and body part injured were retrieved from medical records.

We captured hospital electronic and paper-based data into the data collection database from ED patient records or hospital inpatient discharge system. To eliminate the possibility of duplicate cases, those reported in ED and hospitalisation records were considered as a single injury case with the highest severity of injury outcome documented. Police reports, originally in Arabic, were translated into English and relevant variables were abstracted into the RedCap database.

\section{Patients and public involvement}

No patients were involved in this present study. Patients and the public were not involved in any way in setting up the research priority, defining the research question and outcome measures, providing input on the study design and conduct, disseminating study results or evaluating the study.

We cleaned collected data, compiled and fused into a single child transport injury database. Duplicate cases of hospital medical records and police reports were removed. Most police reports were minor injuries. Nonetheless, moderate to severe injury cases that were documented 
by the police at crash sites and resulted in hospital ED presentations for further medical treatment were identified and removed from our database to eliminate duplication. We identified and removed duplicate cases based on identifying and matching four key variables: (1) hospital name, (2) child age, (3) date of injury and (4) location of injury. In case of a duplicate case, we decided to exclude the police report of the case and keep its hospital record as it encompasses more clinical details of the injured case.

We conducted descriptive and inferential statistical analyses using STATA V.14, to describe the causes and patterns of child's RTI in the population. We calculated the rates based on child population-denominator in each governorate, computed from the percentage of children aged $0-17$ years in Lebanon. ${ }^{21}$ We used $\chi^{2}$ tests to test the bivariate association between the different contributing factors of RTI and different outcomes (injuries and/or fatalities), and we adopted logistic regression models to study the association of multiple simultaneous factors on the injury outcome and severity. We performed logistic regression models to test the multivariate association of the main outcome variables (eg, death, head and neck injuries, and extremity injuries) and each of the following covariates: type of road victim, gender, age, nationality and season, in addition to a set of variables related to the nature of the accident (distracted driver due to phone use, exceeding speed limits, careless pedestrian crossing of the road, wrongfully overtaking another vehicle and intentional hit); we used stepwise regression analysis (with a probability of entry of 0.1 and a probability of removal of 0.2) to select which of the variables related to the nature of the accident were to be retained. The initial full model contained 25 variables. All three regression models were stratified by nationality (Lebanese vs Syrian) as it was considered an effect modifier. An alpha level of 0.05 was used to determine statistical significance.

\section{RESULTS}

A total of 3,270 cases of children's RTI cases were collected for the period of 3 years between January 2015 and December 2017. The rates of child RTIs and deaths varied across geographic locations and were substantially higher in outlying governorates compared with the capital city Beirut (76.7 per 100000 population) with rates ranging from 103.56 in Beqaa, 101.06 in Akkar, 91.76 in Baalbek, 97.59 in South, 66.56 in Nabatiyeh, and 48.56 in Mount Lebanon per 100000 population (table 1) (figure 1).

Across all ages and nationalities, males had higher proportions $(0.72, n=2,354)$ of transport injuries compared with females for all types of transport modes (mean (SD) age $=11( \pm 5)$ years $)$. Approximately $48 \%$ of child's RTI victims were vulnerable road users (ie, pedestrians, motorcyclists and cyclists). Almost two-thirds of these victims were Lebanese $(66.5 \%, \mathrm{n}=2140)$, while the rest were Syrian $(27.9 \%, \mathrm{n}=895)$ and Palestinian $(2.4 \%, \mathrm{n}=75)$. Lebanese children made up the majority of the four-wheel vehicle victims $(36.1 \%, \mathrm{n}=786)$, compared with Syrian children. We grouped children's age into 3 main categories: $0-5$ years, 6-14 years and 15-17 years. Children aged 6-14

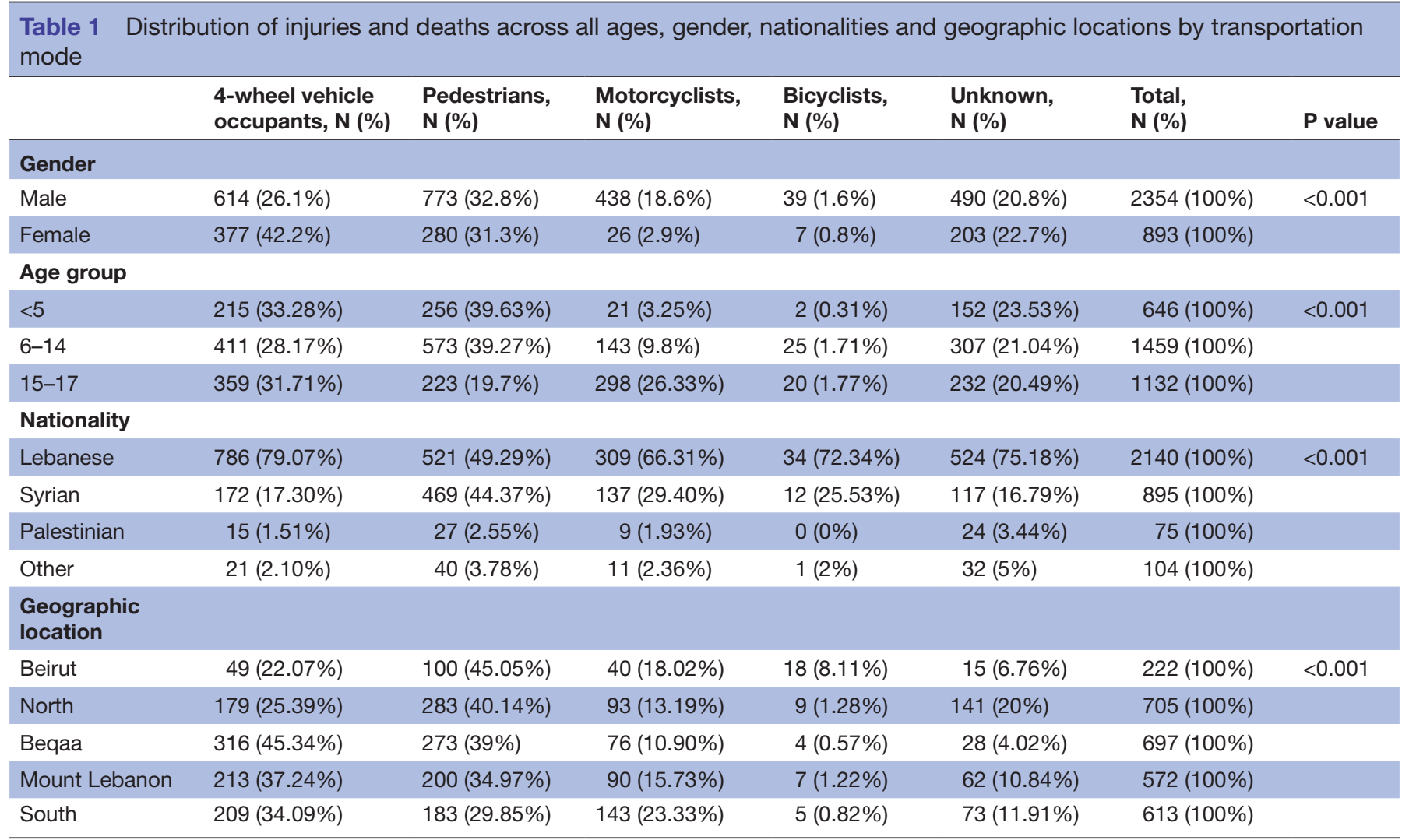




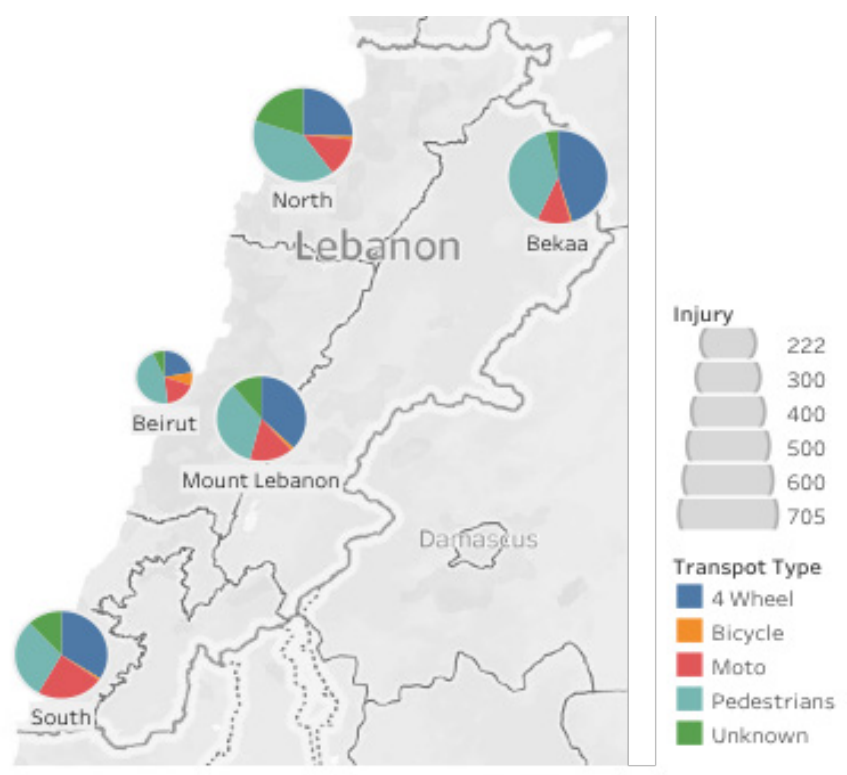

Figure 1 Distribution of road traffic injuries (RTIs) and deaths per governorate (colours referring to each transportation type and the size of the bubbles referring to the RTI).

years had the highest share of transport injuries $(45.2 \%$, $\mathrm{n}=1459)$ compared with those aged $0-5$ years $(18.8 \%$, $\mathrm{n}=646)$ and $15-17$ years $(34.8 \%, \mathrm{n}=1132)$ (table 1$)$. The age group of 15-17 years suffered from a high proportion of motorcycle injuries $(9.2 \%)$ compared with children aged $6-14$ years $(4.4 \%)$ and $0-5$ years $(0.7 \%)$ (figure 2 ). Males were at a higher risk of sustaining motorcyclerelated injuries $(18.6 \%)$ compared with females $(2.9 \%)$. Transport injury morbidity and mortality increased as children's age increased, with significantly higher proportions reported among those aged 15 years $(9 \%), 16$ years $(11 \%)$ and 17 years $(14 \%)$ (figure 2). Children in the oldest age group of 15-17 years were more likely to suffer transport injuries and deaths related to speed and distracted drivers, compared with pedestrians $(p<0.001)$. Within each age group, the distribution of transport injuries varied substantially; younger age groups were more susceptible to being pedestrian road victims $(39.6 \%)$ compared with the oldest age group who were mostly victims of four-wheel vehicles $(31.7 \%)$ and motorcycle $(26.3 \%)$ collisions.

A significant proportion of reported child road injuries occurred on two-way roads not physically divided $(50.5 \%)$, while $18.7 \%$ occurred on side streets and $13 \%$ on highways.

The most commonly reported factors contributing to child's RTI were children occupants of vehicles travelling at high-speed rates (25\%), children in vehicles with distracted drivers (20\%) and children pedestrians crossing roads (14\%). Upper and lower extremities were the most affected body parts (29.9\%), followed by head $(26.1 \%)$ and trunk (12.7\%) (figure 3). Most injuries were superficial, including bruises and abrasions $(36 \%)$, fractures $(23 \%)$, open wounds $(18 \%)$, and minor cuts and lacerations. Weather conditions were not associated with any increased risk of injury; in fact, $55.4 \%$ of reported injury cases occurred on a dry surface. However, the patterns of child injuries changed across seasons with a significant peak in the summer months $(32 \%)$, followed by spring (24\%), fall (23\%) and winter (20\%) (figure 4).

The study uncovered a number of cases in which children were drivers of four-wheel vehicles $(n=140)$ and motorcycles $(n=313)$. Underage children drivers and motorcyclists sustained an increased risk of fatal injuries with fatality proportions of $16.4 \%$ and $6.4 \%$, respectively. The proportion of road victims who were children drivers increased with age. The majority of underage driver victims were males $(88.9 \%$ of four-wheel vehicle drivers and $99.8 \%$ of motorcycle riders). Rural and urban areas alike reported high proportions of underage drivers.

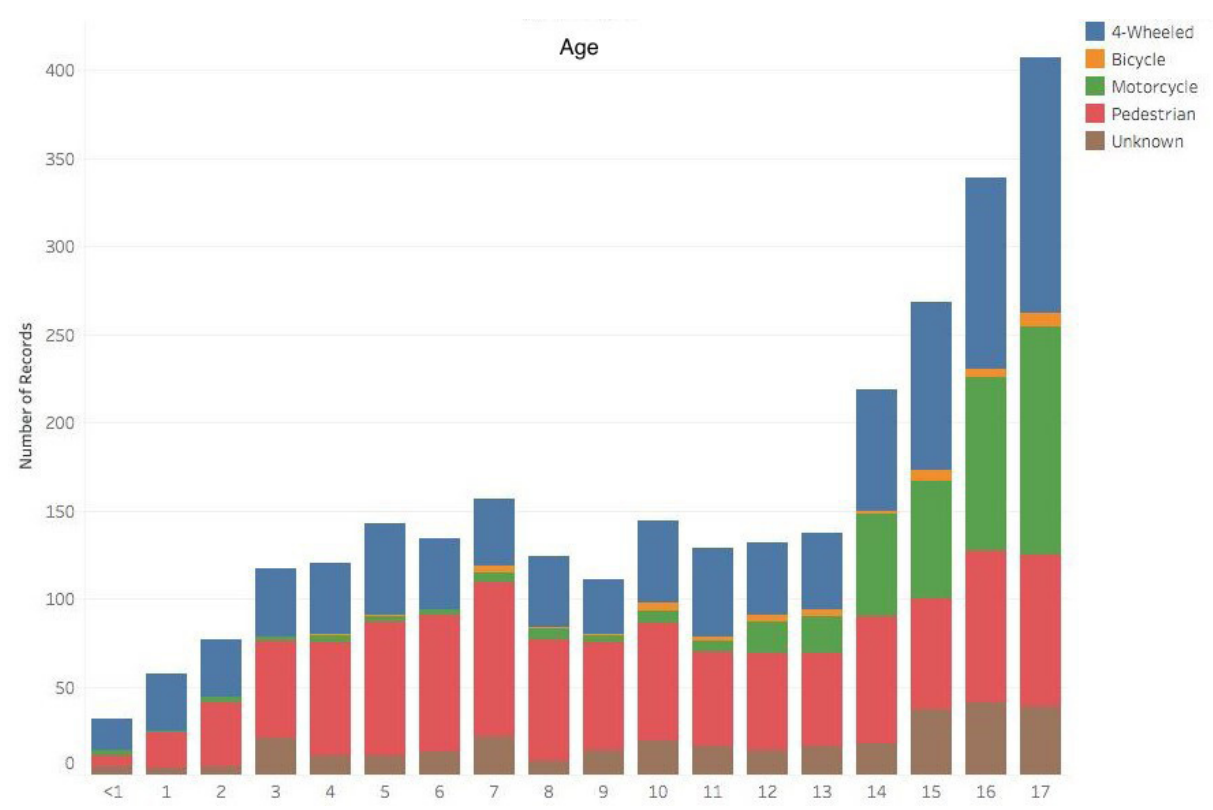

Figure 2 Distribution of injuries and deaths across all ages by transportation mode. 


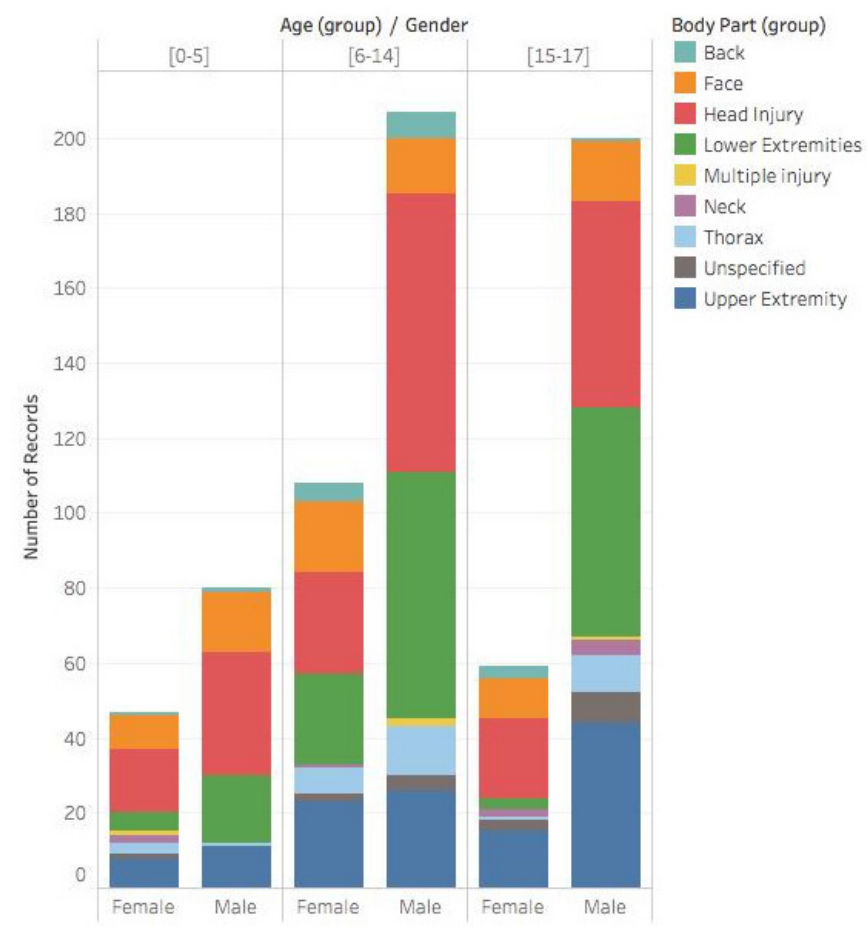

Figure 3 Distribution of RTI by age/gender/body part injured.

The study reported 237 child fatalities $(7.3 \%$ of the total number of cases), 171 males (72\%) and 66 females (28\%). There was no statistical difference in deaths proportions between males and females; $7.3 \%$ of males as RTI victims sustained fatal injuries compared with $7.2 \%$ of females. The $6-14$-year age group experienced the highest proportion of fatalities $(42.3 \%)$, followed by those aged $0-5$ years $(31.4 \%)$ and $15-17$ years $(26.2 \%)$. The difference among age groups was statistically significant $(p<0.001)$. However, the ratio of fatality to injury was highest among the $0-5$ age group with almost $13.9 \%$ of those injured die as a result of their injuries.
Based on the unadjusted regression analysis, pedestrians had higher odds of sustaining fatal injury compared with four-wheel vehicle occupants (OR=1.9; 95\% CI: 1.30 to 2.70 ). The younger age group of $0-5$ years had higher odds of dying from transport injuries compared with the older age group of $15-17$ years $(\mathrm{OR}=1.95 ; 95 \%$ CI: 1.31 to 2.90 ) (table 2 presents the results of the stratified regression analysis). Syrian children had two times higher odds of dying as a result of road injuries as pedestrians compared with Lebanese children $(\mathrm{OR}=2.03 ; 95 \%$ CI: 1.08 to 3.81$)$. Lebanese children aged $6-14$ years had higher odds of fatal transport injuries (OR 0.42; 95\% CI 0.26 to 0.67 ), while Syrian children had higher odds of fatal road injuries among the older age group of 15-17 years (OR $0.43 ; 95 \%$ CI 0.23 to 0.77 ). There were no statistical differences in the death as an outcome for gender and seasons.

Adjusting for all the other variables, the study reveals that age and gender were significant predictors of head and neck injuries for Lebanese children. Females had higher odds of sustaining head and neck injuries compared with males $(\mathrm{OR}=0.75$; $95 \%$ CI: 0.57 to 0.99$)$. Older age group of 6-14 years had lower odds of sustaining head and neck injuries $(\mathrm{OR}=0.73 ; 95 \%$ CI 0.52 to 1.01$)$, compared with the youngest age group of $0-5$ years. Moreover, the analysis showed that contrary to head and neck injuries, older age Lebanese children of 6-14 years and 15-17 years had higher odds of sustaining injuries to extremities compared with the youngest age group of $0-5$ years with $\mathrm{OR}=2.13$ (95\% CI: 1.43 to 3.17 ) and $\mathrm{OR}=2.3$ (95\% CI: 1.55 to 3.53 ), respectively (table 2 ; figures $5-7$ ).

\section{DISCUSSION}

RTI is one of the leading causes of child deaths and disabilities in the Eastern Mediterranean region, including Lebanon. ${ }^{9-11}$ To the best of our knowledge, this is the first study that captures comprehensive national data on child

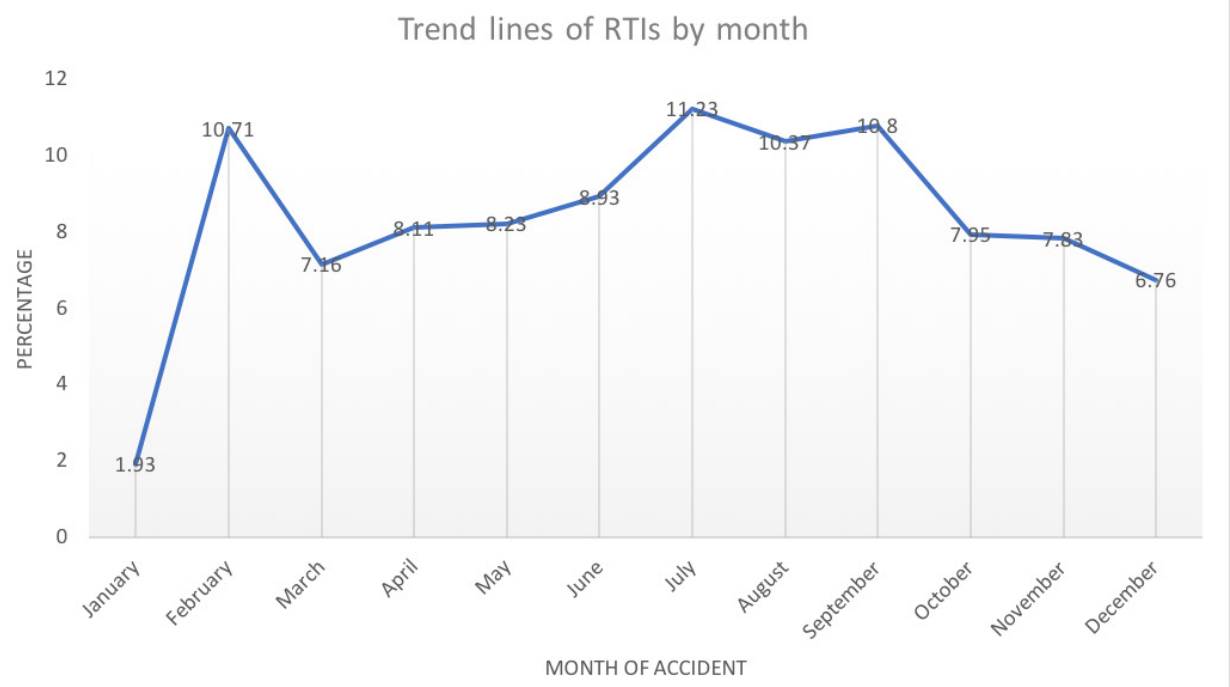

Figure 4 Trend line of child aggregated road injuries and deaths data over a period of 3 years (2015-2017). 
Table 2 OR for deaths, head and neck injuries, and extremities injuries across ages, gender and nationalities

\begin{tabular}{|c|c|c|c|c|c|c|}
\hline & \multicolumn{2}{|c|}{ Death* } & \multicolumn{2}{|c|}{ Head and neck } & \multicolumn{2}{|c|}{ Extremities } \\
\hline & OR & $95 \% \mathrm{CI}$ & OR & $95 \% \mathrm{Cl}$ & OR & $95 \% \mathrm{CI}$ \\
\hline \multicolumn{7}{|c|}{ Gender, female (ref) } \\
\hline \multicolumn{7}{|c|}{ Age, $15-17$ years (ref) } \\
\hline $6-14$ years & 1.03 & 0.74 to 1.42 & 1.26 & 0.86 to 1.83 & 0.91 & 0.73 to 1.14 \\
\hline \multicolumn{7}{|c|}{ Nationality, Lebanese (ref) } \\
\hline Syrian & 2.12 & 1.53 to 2.94 & 0.52 & 0.34 to 0.79 & 0.62 & 0.34 to 1.12 \\
\hline Palestinian & 1.28 & 0.57 to 2.87 & 0.48 & 0.29 to 0.80 & 0.47 & 0.26 to 0.86 \\
\hline Others & 1.24 & 0.44 to 3.49 & 1.06 & 0.41 to 2.71 & 0.79 & 0.39 to 1.60 \\
\hline
\end{tabular}

*The regression model predicting death was also adjusted for head and neck injuries and extremity injuries in addition to all other variables.

road injuries and deaths in Lebanon. Evidence generated from this study will help to gain an understanding of the magnitude and extent of the child's RTI burden and to develop child road injury prevention initiatives and intervention strategies to reduce child mortality and morbidity in Lebanon.

This present study showed that male road victims were over-represented in our cohort. While transport injuries equally affected both males and females of the young age groups, a gender gap appeared and widened as children grew into their teenage years, with nearly three-fourths of the victims aged 14-17 years being males. A plausible explanation rests in the males' increased mobility as well as their engagement in more risky behaviours compared to their females' counterparts. Child's age was a major predictive factor of injury severity and outcome. Our study clearly indicated the significant increase in child transport morbidity and mortality with age, triggered at the age of 14 and peaked as children reached their 16 years and 17 years of age. Existing studies confirmed our results and indicated that gender and age are among the main factors associated with road injury severity and fatalities. $^{326-30}$

Body part injured was another predictive factor of RTI severity and outcome. Agreeing with evidence from the literature, our study results identified a high proportion of head and extremity injuries, both of which are significantly associated with severe road injuries and deaths. ${ }^{26-30}$

One of the major findings of this study is the high prevalence of fatal road injuries among children aged 0-5 years, revealing children's physical vulnerability in road crashes. Those young age children suffered the highest

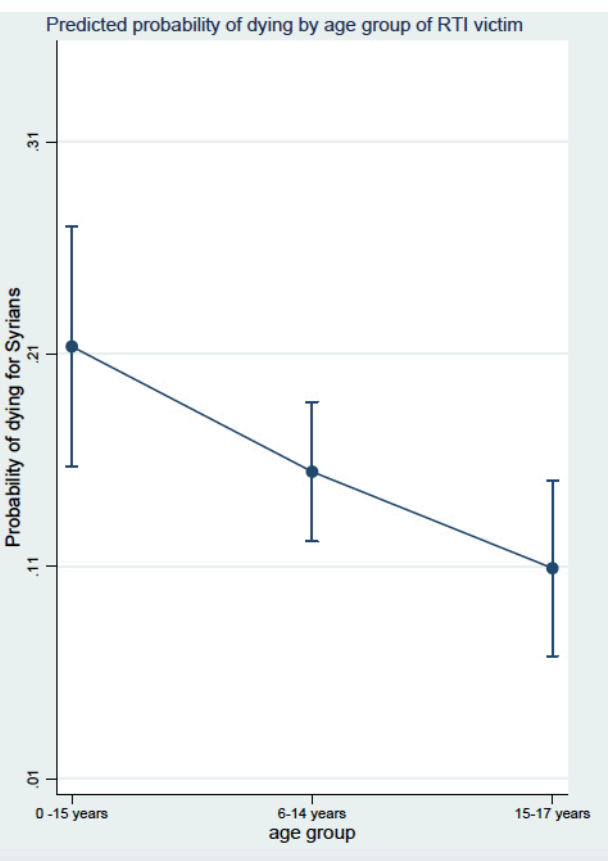

Figure 5 Predicted probability of death among age groups of 0-5 years, (6-14) years and (15-17) years, respectively, between Lebanese and refugee children. 


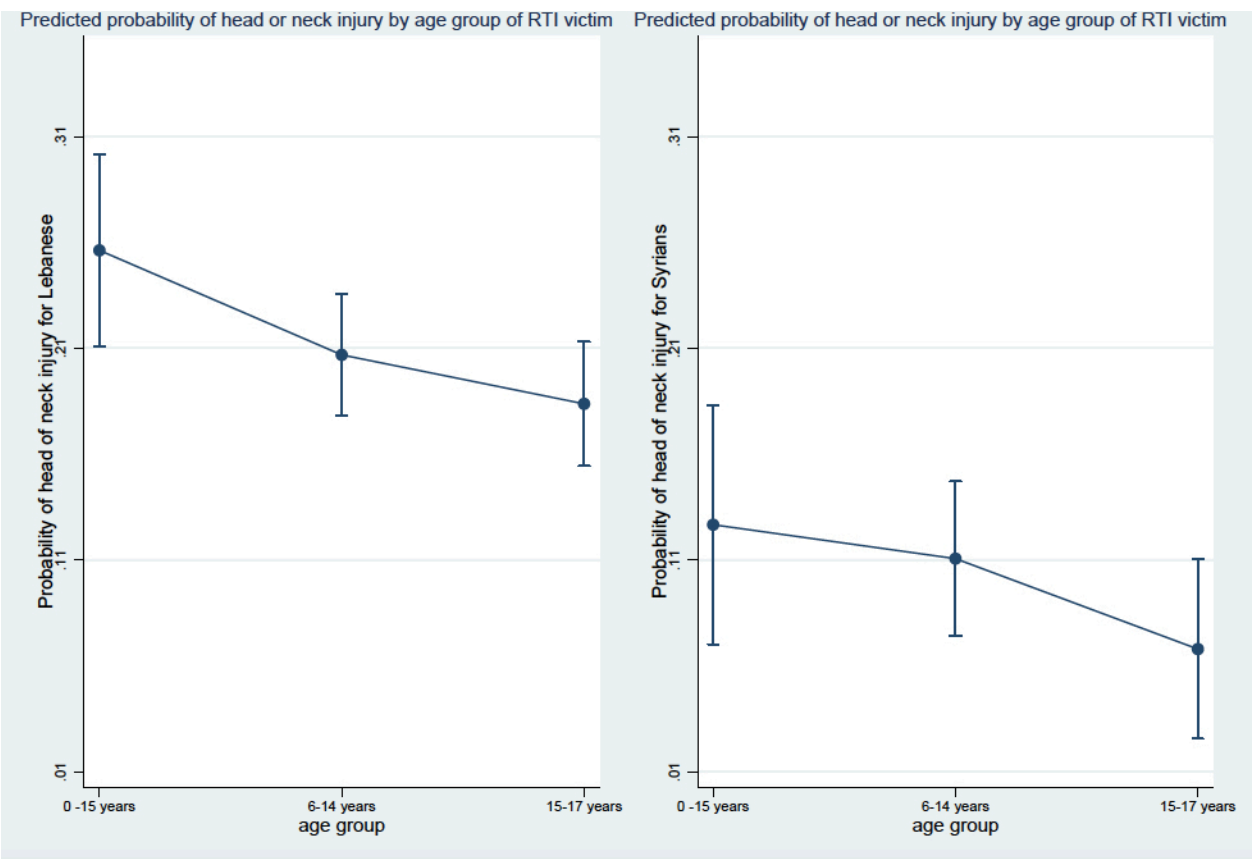

Figure 6 Predicted probability of head and neck injuries among age groups of 0-5 years, (6-14) years and (15-17) respectively, between Lebanese and refugee children.

proportion of road fatalities, approximately twofold the proportion reported in the older age group of 15-17 years. The increased fatalities among the $0-5$-year children population are further supported by evidence drawn from the high proportion of head and neck injuries sustained by the same age group population. This underscores the association between body part and injury outcome and emphasises the vulnerability and low physical tolerance of a child's body in high-impact collisions. As a child's body is mostly head and spinal cord, its centre of gravity is positioned upward and its underdeveloped spinal cord muscle has limited control of the head weight and motion in high-impact collisions. ${ }^{26}$ An ample number of evidence indicated that road-related head trauma and the increased risk of sustaining fatal road injuries are primarily associated with the lack of compliance with safety measures (ie, helmet and seatbelt/child restraint system). ${ }^{26-30}$ In Lebanon, weak compliance with children restraint system regulations is predominately observed among parents, which suggests that the majority

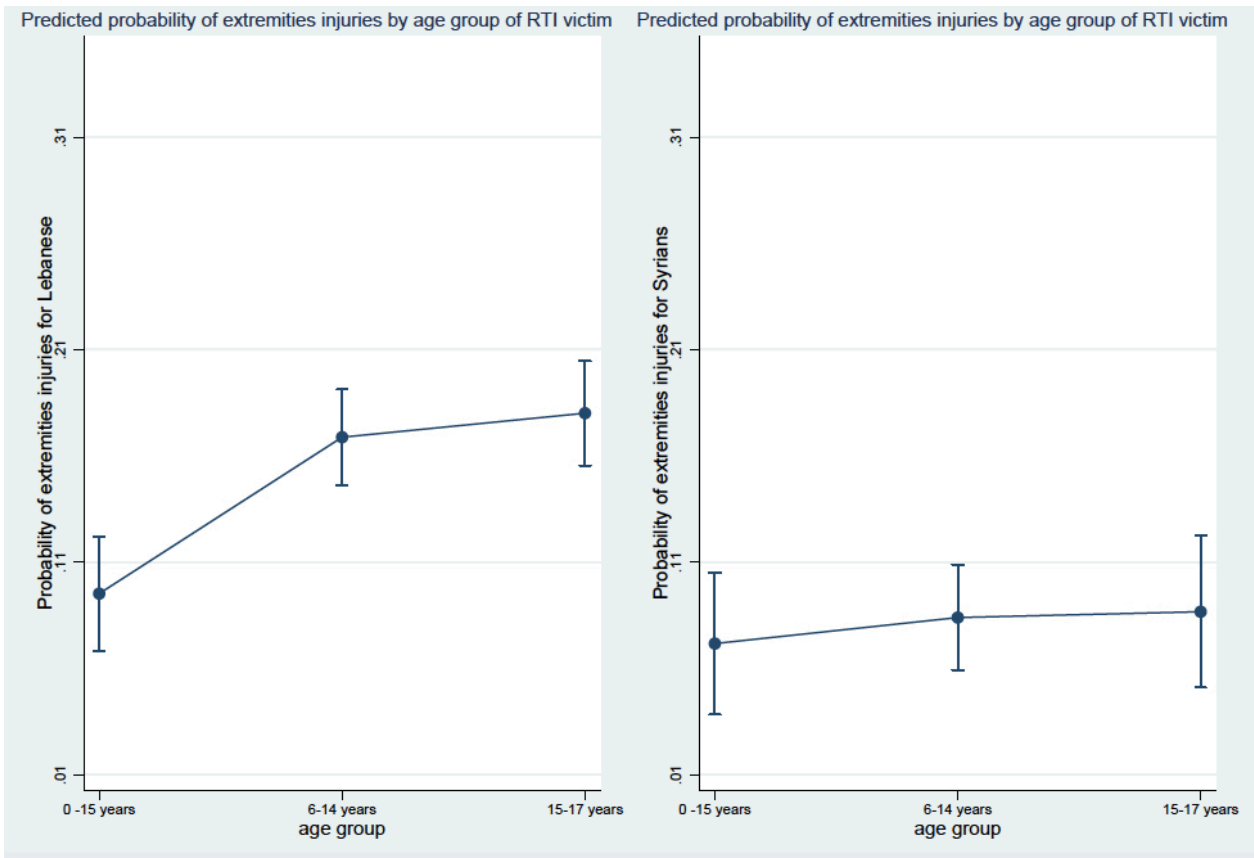

Figure 7 Predicted probability of extremities injuries among age groups of $0-5$ years, (6-14) years and (15-17) years, respectively, between Lebanese and refugee children. 
of children who sustained severe head injuries or deaths were more likely unrestrained in vehicles. Despite the fact that Lebanese recent 2012 traffic laws (Laws 18 and 61) require the use of protective equipment (ie, helmets and seatbelts) and child restraint systems and specify speed limit at major highways and near schools. ${ }^{31}$ Nonetheless, many elements of these laws and regulations are not firmly monitored nor strictly enforced. Driven by cultural and social norms, parents adopt unsafe road behaviours and practices, including placing a child on a mother's lap (front passenger seat) or behind the steering wheel.

Based on the study analyses, the majority of child transport injuries and deaths were among vulnerable road victims, mainly pedestrians, cyclists and motorcyclists, making the 'type of road victims' an additional predictor of injury severity and outcome. Pedestrians sustained almost a 2-fold risk of death compared with occupants of 4 -wheeled vehicles. These findings align with several RTI studies conducted in low- and middle- income countries where many poor families with low socio-economic status rely on commuting as vulnerable road users (pedestrians, motorcyclists and cyclists) and they are forced to share the road with the motorised traffic, thus increasing their risk of road injuries. ${ }^{326-30}$ Moreover, road infrastructure exacerbates the child's RTI problem and significantly increases children's risk of road fatal and non-fatal injuries. Our study findings reveal that a significant proportion of severe injuries and hospital deaths on arrival occurred on roads with two-way traffic, not physically divided. This calls for the government to take injury prevention measures to enhance pedestrians' safety, including the installation of road dividers and medians, roundabouts, speed bumps and lit crosswalks. Finally, the seasonal trends and the reportedly high road injuries and deaths during the warm and hot seasons is attributable to children's outdoor activities and increased mobility during the summer season.

Outlying regions with limited access to healthcare facilities were disproportionally affected and burdened with a high toll of child road injuries and deaths. With nearly $78 \%$ of the Lebanese population living in urban areas, most essential healthcare services are centred in the city's hospitals and trauma centres. A recent study indicated the disparities in healthcare resources and access to healthcare services across Lebanon governorates, with limited healthcare infrastructure in remote locations, particularly within refugees' dense areas in the North and beqaa regions. ${ }^{32}$ This present study sheds light on the issue of health inequity and limited accessibility to health services across these remote locations. Investing in rural emergency medical service delivery and access to timely clinical interventions are critical to improving treatment and curtailing the increased number of preventable transport deaths. Further to the lack of critical health services, rural areas suffer from the absence of law enforcement, which was manifested in the increased number of underage drivers in different outlying governorates, namely in the North and South. Despite the fact that the legal driving age in Lebanon is 18 years, this study found that children as young as 12 years of age were involved in road collisions as vehicle and motorcycle drivers. Children's limited physical development and cognitive capabilities to perceive risks and adopt preventive actions increase their risk of being exposed to transport injuries. Among older children, behavioural issues such as risk-taking behaviour, lack of experience and peer and social pressure increase their risk of sustaining fatal injuries.

The study has some key strengths. The main strength of this present study rests in its combination of multiple sources of data (hospital patient records and police reports) to reveal for the first-time evidence on the child transport injuries and deaths in Lebanon. Moreover, the study population is deemed representative, hence, increasing the generalisability of the study findings.

The study has some limitations. Firstly, due to the retrospective nature of the study, access to hospital and police secondary data hindered the capturing of essential elements related to the injury mechanism and severity (eg, Injury Severity Score and Glasgow Coma Scale). Collected hospital data were administrative and clinical data and, therefore, lack critical information on the mechanism of injury, which may hinder our understanding of the injury burden as well as limit the impact of the generated evidence from informing injury policy and designing targeted child injury prevention programmes. Moreover, the nature and type of injuries were not uniformly reported across hospital and police data. Secondly, this study might have underestimated the actual national burden of child transport injury because it does not account for minor injuries and only captured injuries requesting police investigation or medical attention and presentation at emergency departments. Thirdly, police reports had a noticeable high number of minor injuries reported, there is a possibility that these reports have missed children's invisible injuries (eg, fractures, cerebral contusion, etc) that can have significant outcomes (eg, permanent disabled or deaths). Lastly, a limited number of child's RTI cases documented child restraint status and position in the car, a major predictor of transport injury severity and outcome, with a large implication on child road safety prevention and strategies.

This study calls on government officials, policy-makers, non-governmental organisations and health advocates to adopt the generated evidence in order to design and implement child injury prevention measures and programmes. A series of strategic recommendations can be implemented with the aim to reduce child injuries and deaths on the roads as follows.

\section{Establish a national injury surveillance system and ensure proper injury coding}

Hospital-based injury surveillance will help to capture consistent and harmonised injury data, which are essential to understand the injury morbidity and mortality rate at the national level and assess the country's actual RTI 
burden. Adopting a universal coding scheme is vital to unify the classification and reporting of RTI injury data.

\section{Enforce transport safety laws, particularly those intended to protect children}

Strong political will and government commitment should be directed towards enforcing child safety legislation (ie, prohibit over-capacity vehicle occupancy, use of helmet, seatbelt and child restraint system) and mobilising primary prevention efforts to control child transport injuries and deaths.

\section{Implement evidence-based transport safety policies and behaviour change programmes and invest in safer road infrastructure}

Successful and cost-effective road injury prevention strategies and interventions should be contextualised and adapted to serve local communities. Awareness campaigns and behavioural change programs should be integrated to educate individuals and encourage safe behaviour among pedestrians and drivers.

\section{CONCLUSIONS}

This is a unique study that combines multiple sources of data to build a comprehensive estimate of the burden of child road injuries and deaths in Lebanon. This study was the first to be carried out at the national level to gain a deep understanding of the demographic, ethnic and geographic distribution of child road injuries and deaths across Lebanon. The study urges government, public institutions and development agencies to adopt the study evidence to inform public road safety policies (e.g. speed limits, seatbelt, helmet, child restraint and underage drivers), to improve road infrastructure i e.g. raised pavement for pedestrians, dedicated and lit crosswalks, median barriers and speed bumps) and essentially to ensure adherence to these regulations. Moreover, the study provides evidence for social change, aimed at encouraging safe behaviour among pedestrians and drivers alike. Further research is needed to generate evidence and provide data-driven injury prevention and control measures that can eventually lead to the reduction of child road injuries and fatalities.

\section{Twitter Samar Al-Hajj @DrSamarHajj}

Contributors SA-H has contributed to the conception, overseeing data collection, cleaning and analysis process, as well as writing, reviewing and editing the manuscript. SA has contributed to the data collection, manuscript writing and data analysis process. $\mathrm{ZH}$ has contributed to the data collection, data cleaning process and supported with the initial writing. EA-Z has contributed to the data collection at emergency rooms and initial writing of the manuscript. KEA has contributed to the data analysis and review of methodology and results sections. All authors have read the manuscript and agreed that the work is ready for submission and accept responsibility for its contents.

Funding This research was funded by Save the Children International (CON-B2018-020). The funders had no role in study design, data collection and analysis, decision to publish, or preparation of the manuscript

Map disclaimer The depiction of boundaries on this map does not imply the expression of any opinion whatsoever on the part of BMJ (or any member of its group) concerning the legal status of any country, territory, jurisdiction or area or of its authorities. This map is provided without any warranty of any kind, either express or implied.

Competing interests None declared.

Patient consent for publication Not required.

Ethics approval The study ethical approval was obtained from the institutional review board of the American University of Beirut (BI0-2018-0459) and from the ethical committee of each participating hospital. This manuscript reflects original work that has not previously been published in whole or in part and is not under consideration elsewhere. The authors have read the manuscript and have agreed that the work is ready for submission and accept responsibility for its contents. The authors of this paper have complied with all ethical standards and do not have any conflicts of interest to disclose at the time of submission.

Provenance and peer review Not commissioned; externally peer reviewed.

Data availability statement Data are available upon reasonable request. Data compiled from this study will be shared publicly. Hyperlink to the archived dataset will be accessible upon manuscript publication.

Supplemental material This content has been supplied by the author(s). It has not been vetted by BMJ Publishing Group Limited (BMJ) and may not have been peer-reviewed. Any opinions or recommendations discussed are solely those of the author(s) and are not endorsed by BMJ. BMJ disclaims all liability and responsibility arising from any reliance placed on the content. Where the content includes any translated material, BMJ does not warrant the accuracy and reliability of the translations (including but not limited to local regulations, clinical guidelines, terminology, drug names and drug dosages), and is not responsible for any error and/or omissions arising from translation and adaptation or otherwise.

Open access This is an open access article distributed in accordance with the Creative Commons Attribution Non Commercial (CC BY-NC 4.0) license, which permits others to distribute, remix, adapt, build upon this work non-commercially, and license their derivative works on different terms, provided the original work is properly cited, appropriate credit is given, any changes made indicated, and the use is non-commercial. See: http://creativecommons.org/licenses/by-nc/4.0/.

ORCID iD

Samar Al-Hajj http://orcid.org/0000-0002-4736-021X

\section{REFERENCES}

1 GBD. Causes of death Collaborators. global, regional, and national age-sex-specific mortality for 282 causes of death in 195 countries and territories, 1980-2017: a systematic analysis for the global burden of disease study 2017. The Lancet. 8 Nov 2017;2018:1736-88.

2 Krug EG, Sharma GK, Lozano R. "The Global Burden of Injuries." American journal of public health 90;4:523.

3 World Health Organization. Global status report on road safety, 2018.

4 World Health Organization. Save lives: a road safety technical package, 2017. Available: https://www.who.int/violence_injury_ prevention/publications/road traffic/save-lives-package/en/

5 World Health Organization. Youth and road safety, 2007. Available: https://www.who.int/management/programme/ncd/Youth\%20and\% 20Road\%20Safety.pdf

6 World Health Organization. Global plan for the decade of action for road safety 2011-2020, 2011. Available: http://www.who.int/ roadsafety/decade_of_action/plan/en/

7 United Nations General Assembly. Transforming our world: the 2030 agenda for sustainable development, 2015. Available: https://sust ainabledevelopment.un.org/post2015/transformingourworld

8 Peden M. World report on road traffic injury prevention. Geneva: World Health Organization, 2004. http://www.who.int/violence_injury_ prevention/publications/road_traffic/world_report/en/

9 Dalal K. Transport injuries and deaths in the Eastern Mediterranean Region: findings from the Global Burden of Disease 2015 Study. In: International Journal of public health, 2017.

10 Mokdad AH. Adolescent health in the eastern Mediterranean region: findings from the global burden of disease 2015 study. Int J Public Health 2017:1-8.

11 Al-Hajj S, El Bcheraoui C, Daoud F, et al. Child and adolescent injury burden in the eastern mediterranean region: Findings from the Global Burden of Disease 1990-2017. BMC Public Health 2020;20:433.

12 Choueiri EM, Aoun J, Otayek EJune. Effectiveness of the newly introduced variable message signs in Lebanon on driver behavior. 
In: In models and technologies for intelligent transportation systems (MT-ITS), 2017 5th IEEE International Conference on, 2017: 562-7.

13 Choueiri B, Choueiri G, Choueiri EM. An overview of road safety in Lebanon with particular attention to non-urban roads. Advances in transportation studies 2007;11:75-91.

14 Choueiri EM, Choueiri GM, Choueiri BM. An overview of land transport in Lebanon, with special emphasis on traffic safety. Advances in Transportation Studies 2012;28:63-80.

15 Choueiri EM, Choueiri GM, Choueiri BM. Road safety in Lebanon: magnitude, cost and potential countermeasures. Advances in Transportation Studies 2015;35:73-88.

16 Al-Hajj S, Pawliuk C, Smith J, et al. History of injury in a developing country: a scoping review of injury literature in Lebanon. J Public Health 2020. doi:10.1093/pubmed/fdaa043. [Epub ahead of print: 23 Apr 2020].

17 United Nations High Commission on Refugees. Syria regional refugee response - Lebanon - June 2018, 2016. Available: http:// data.unhcr.org/syrianrefugees/country.php?id=122; [Accessed September 2019].

18 Ouyang $\mathrm{H}$. Syrian refugees and sexual violence. Lancet 2013:381:2165-6.

19 Al-Hajj S, Pike I, Oneissi A, et al. Pediatric burns among refugee communities in Lebanon: evidence to inform policies and programs. J Burn Care Res 2019;40:769-75.

20 El Asmar M. Beirut, Lebanon: social sciences department, Lebanese American university, 2013. Available: http://mepitl.lau.edu.lb/images/ FinalVersionCapstoneMargeritta.pdf

21 Lebanon Population. Available: https://www.worldometers.info/ world-population/lebanon-population/ [Accessed May 20, 2020].

22 Lebanon.(2017, September 15)from. Available: http://www. healthdata.org/lebanon [Accessed May 20, 2020].
23 Available: R. Available: https://www.project-redcap.org; [Accessed September 2019].

24 Crain J, McFaull S, Thompson W, et al. Status report - The Canadian Hospitals Injury Reporting and Prevention Program: a dynamic and innovative injury surveillance system. Health Promot Chronic Dis Prev Can 2016;36:112-7.

25 Holder Y \& World Health Organisation Staff. Injury surveillance guidelines. Geneva: World Health Organization, 2002.

26 Brolin K, Stockman I, Andersson M, et al. Safety of children in cars: a review of biomechanical aspects and human body models. IATSS Research 2015;38:92-102.

27 El-Menyar A, Consunji R, Asim M, et al. Underutilization of occupant restraint systems in motor vehicle injury crashes: a quantitative analysis from Qatar. Traffic Inj Prev 2016;17:284-91.

28 Hilton J, Shankar U. Motor vehicle traffic crashes injury and fatality estimates early assessment, 2001. Available: https://ntlrepository. blob.core.windows.net/lib/19000/19600/19657/PB2002108600.pdf [Accessed $2002 \mathrm{Apr}$ ].

29 Ball CG, Kirkpatrick AW, Brenneman FD. Noncompliance with seatbelt use in patients involved in motor vehicle collisions. Can J Surg 2005;48:367.

30 Nantulya VM, Reich MR. The neglected epidemic: road traffic injuries in developing countries. BMJ 2002;324:1139-41.

31 Internal Security Forces. The new traffic law, 2012. Available: http:// www.isf.gov.lb/files/law243.pdf

32 Kaafarani HMA, Khalifeh JM, Ramly EP, et al. A nationwide, systematic, and comprehensive assessment of surgical capacity in Lebanon: results of the surgical capacity in areas with refugees (scar) study. Ann Surg 2019;269:1206-14. 